\title{
Molecular imprinting technology for microorganism analysis
}

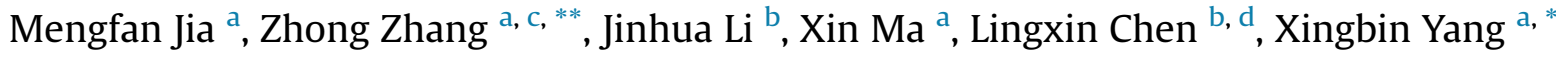 \\ a Shaanxi Engineering Laboratory for Food Green Processing and Safety Control, College of Food Engineering and Nutritional Science, Shaanxi Normal \\ University, Xi'an, 710119, China \\ ${ }^{\mathrm{b}}$ CAS Key Laboratory of Coastal Environmental Processes and Ecological Remediation, Research Center for Coastal Environmental Engineering and \\ Technology, Yantai Institute of Coastal Zone Research, Chinese Academy of Sciences, Yantai, 264003, China \\ ' School of Chinese Medicine, Li Ka Shing Faculty of Medicine, The University of Hong Kong, 10 Sassoon Road, Pokfulam, Hong Kong, China \\ d College of Chemistry and Chemical Engineering, Yantai University, Yantai, 264005, China
}

\section{A R T I C L E I N F O}

\section{Article history:}

Available online 20 July 2018

\section{Keywords:}

Analytical detection

Identification

Microorganism

Molecular imprinting

Biosensor

\begin{abstract}
A B S T R A C T
Molecular imprinting technology has been widely applied to various fields, owing to unique features of structure predictability, recognition specificity and application universality. Microorganism imprinting has attracted significant interests attributing to the high selectivity, simplicity rapidity, and excellent stability as well as low cost and eco-friendliness. Herein, we purpose to review the recent advances of MIT for microorganism analysis, concerning imprinting methods, analytical detection methods and typical applications. Various imprinting methods including direct and indirect imprinting for microorganism-MIPs preparation are comprehensively summarized. MIPs based biosensors containing fluorescence, electrochemical, piezoelectric and surface plasmon resonance for analytical detection of microorganisms is highlighted. Representative applications of microbiological imprinting are discussed, involving detection and quantification of bacteria, identification of bacterial species, and determination of yeast growth status. Finally, we propose the remaining challenges and future perspectives to accelerate the development and utilization of MIT in microorganism analysis and thereby push forwards microorganism identification and determination.
\end{abstract}

() 2018 Elsevier B.V. All rights reserved.

\footnotetext{
Abbreviation: AFM, Atomic force microscopy; B. subtilis, Bacillus subtilis; CV, Cyclic voltammetry; CFU, Colony-forming units; D. radiodurans, Deinococcus radiodurans; E. coli, Escherichia coli; ECL, Electrochemiluminescence; ELISA, Enzymelinked Immunosorbent Assay; FRET, Fluorescence resonance energy transfer; LOD, Limit of detection; JEV, Japanese encephalitis virus; MIPs, Molecularly imprinted polymers; MIT, Molecular imprinting technology; MIM, Microbial imprinted material; NorVLP, Norovirus; N-GQDs, Nitrogen-doped graphene quantum dots; NP, Nanoparticle; OSX, Organosiloxane; PCR, Polymerase chain reaction; PA, Protein A; PFBT, Poly(fluorene-alt-benzothiadiazole); PBA, Phenylboronic acid; PC, Pyrene-1carboxaldehyde; PDA, Polydopamine; QCM, Quartz crystal microbalance; SA, Sialic acid; SEM, Scanning electron microscopy; SIP, Surface imprinted polymer; SNP, Silica nanoparticles; S. natans, Sphaerotilus natans; SPEs, Screen-printed electrodes; SPR, Surface plasmon resonance; SWCNTs, Single walled carbon nanotubes; virus-MIPs, Virus-molecular imprinted polymers; VLP, Virus-like particle.

* Corresponding author. Shaanxi Engineering Laboratory for Food Green Processing and Safety Control, College of Food Engineering and Nutritional Science, Shaanxi Normal University, Xi'an, 710119, China.

** Corresponding author.

E-mail addresses: zzhang@snnu.edu.cn (Z. Zhang), xbyang@snnu.edu.cn (X. Yang).
}

\section{Introduction}

Microorganisms, a kind of microscopic organism, exist in its single-celled form or in a colony of cells, and usually include bacteria, viruses, fungi, and some small protozoa, microalgae, etc. Microorganisms are prevalent in our daily lives, from our skin to our plates, going through all our electronic devices, and are widely studied in many fields [1]. It is estimated that $10 \%$ of crops are lost due to plant diseases caused by microorganisms worldwide every year, which can lead to considerable financial losses for farmers and even social problems especially in developing countries [2]. In clinical trials, microorganisms are a significant threat to human health, especially since the advent of antibiotic resistance and the exit of many pharmaceutical companies based on antibiotic research and development [3]. Waterborne diseases are typically caused by enteric microorganisms such as bacteria, viruses and protozoa, which are basically transmitted by the fecal-oral route [4]. Among food-borne microorganisms, Salmonella, Listeria monocytogenes and enterohemorrhagic Escherichia coli are responsible for several million cases of diseases worldwide each year [5]. Pathogen contamination is a permanent problem in a wide range of 
fields, and researchers are required to recognize and detect them as quickly as possible, which is critical to preventing the outbreak of pathogenic diseases [6]. Therefore, the identification and determination of microorganism becomes increasingly imperative and significant.

Currently, laboratory-based biochemical methods for microorganism analysis are mostly performed by means of classical microbiology methods. Initially, analytical methods were mainly limited to standard antibody assays and nucleic acid-based assays, such as polymerase chain reaction (PCR) and hybridization onto blotted membranes [7]. These methods are primarily based on the detection of specific nucleotide sequences within the pathogen genome or on the detection of pathogen-specific surface epitopes using antibodies $[7,8]$. However, traditional methods have a variety of drawbacks. Firstly, these methods generally require high technical skills and sample preparation procedures, including massive sample cleanup and biomolecule purification [9]. Moreover, current assays are usually label-dependent, which limits them to some specialized laboratories with advanced read-out facilities [10], thus bringing about a risk that humans will be exposed to a contaminated environment for a longer time. Therefore, it is an emergent desire in this field to design novel, rapid and reliable analytical detection methods for microorganisms.

Consequently, artificial receptors capable of selectively binding target compounds with high affinity are being designed and fabricated extensively, which are similar to that of the corresponding natural bio-receptors [11]. Among them, molecularly imprinted polymers (MIPs) created by molecular imprinting technology (MIT), have attracted strong interest owing to the unique features of structure predictability, recognition specificity and application universality. MIPs are synthetic polymeric materials with specific recognition sites complementary in shape, size, and functional group to template molecules [12]. MIPs are easily synthesized from various polymers and can be tailor-made for specific analytes at a low cost. As versatile materials, MIPs stand out for their template flexibility, and higher physical robustness and thermal stability than other natural counterparts [13,14]. Thus MIPs have aroused extensive attention in the fields of sample pretreatment, chromatographic separation [15,16], chemical and biological sensors [17] and so on. To date, a number of studies on a variety of small molecules [18,19], proteins [20], and ions [21] based on MIPs have been rapidly carried out. More excitingly, microorganism imprinting was first proposed in 2001 by Dickert et al. [22] using yeast as a template via surface imprinting of polyurethane; this was considered as the most promising branch of MIPs. Furthermore, microorganism imprinting and cell imprinting have recently emerged as research hotspots. As synthetic receptors, MIPs can be devised for a range of microorganisms. For example, Redeker et al. [23] introduced a novel bacterial identification assay based on thermal wave analysis through surface imprinted polymers. The results indicated that the sensor was able to detect bacteria in urine in physiologically relevant concentrations as low as $3 \times 10^{4} \mathrm{CFU} \mathrm{mL} \mathrm{mL}^{-1}$. Dulay et al. [24] reported a biosensor with high sensitivity and selectivity based on the low cost preparation of organosiloxane (OSX) polymers imprinted with E. coli-GFP (green fluorescent protein). The unique shape and chemical fingerprint of the targeted inactivated E. coli-GFP were imprinted into bulk polymers by stamp imprinting. So, for microorganism analysis, the MIPs based strategy has gained much popularity owing to that the MIPs, compared with natural antibodies, have greater stability and larger sensitivity ranges, and they are also able to adapt to extreme conditions [25].

Among different imprinting technologies, the performance of the surface imprinting of microorganism is usually superior to other modalities [26], by controlling templates to locate at the surface or in the proximity of materials' surface to create more effective recognition sites. Numerous research results have proven the potential of imprinting these large and complex microorganisms by surface imprinting. Tawil et al. [27] reported that phage immobilized on gold coated with L-cysteine conjugated and 11mercaptoundecanoic acid, which was very efficient for infecting a population of host bacteria. And atomic force microscopy observations revealed that cavities on gold electrode surface were of a similar diameter and depth as those of the phage capsid. However, excitedly, the characterization of the physical processes of bacteriophage interaction with functionalized Au surfaces and the stability of the resulting complexes is of critical importance to biosensor applications. In Yongabi's research [28], their analysis determined that cell imprinting created selective binding sites on the surface of the imprinted polymer layer, which matched the cell's shape and size in the form of binding cavities. The study demonstrated that the incorporated phospholipids could significantly enhance cell adhesion to the surface imprinted polymers.

Meanwhile, a series of excellent reviews have given thorough accounts of MIT and MIPs. For example, Chen et al. [25] comprehensively reviewed the recent advances in molecular imprinting, including versatile perspectives and applications, concerning novel preparation technologies and strategies of MIT, and highlighted the applications of MIPs for sample pretreatment, chromatographic separation and chemical and biological sensing. Nonetheless, microorganism imprinting is not specifically mentioned. As well as, most of these reviews have placed more emphasis on the fundamental aspects and characteristic applications of MIPs and MIT. For instance, Ozin et al. [29] aimed at the key aspects of imprinted silica-based materials as demonstrated by judiciously controlled systems, looking first at control on the micrometer scale in bulk phase materials, and then on the nanometer scale in templated mesoporous materials. Li et al. [30] primarily concerned some key issues involved in the imprinting of macromolecules, as well as the similarities and differences between small molecules and macromolecules imprinting. Zhang et al. [31] focused on the design and utilization of molecular imprinting fluorescent sensors, especially new preparation strategies, detection mechanisms and sensing applications. However, none of the reviews aforementioned comprehensively involve the development status, applications and trends of microorganism imprinting. To the best of our knowledge, there are few reviews on MIT related to the recognition and detection of microorganisms.

This review, therefore, focuses on the MIT for microorganism analysis, with an emphasis on recent advances within 2012-2018. Firstly, we summarize the imprinting methods for microorganism, including both direct and indirect imprinting. Secondly, we highlight pathogenic analytical detection methods coupled with MIP systems, including fluorescent, electrochemical, piezoelectric and surface plasmon resonance (SPR) biosensors. Thirdly, we discuss the applications of microbiological imprinting in diverse fields, focusing on the detection and quantification of bacteria, the identification of bacterial species and the determination of yeast growth status changes. Finally, we propose the remaining challenges and future perspectives for improving the applications of MIT in microorganism analysis.

\section{Imprinting methods of microorganism}

Microorganism imprinting, which use microorganism (including bacteria, viruses, yeast and cells) as template, is a kind of molecular imprinting. According to different imprinting materials, microorganism imprinting can be classified into sol-gel materials, electrochemical deposition materials and polymer materials. According to different imprinting methods, microorganism 
imprinting can be introduced into both direct and indirect imprinting, and the characteristics of these different imprinting methods of microorganism are summarized in Table 1.

\subsection{Direct imprinting}

The simplest method to achieve high selectivity in microorganism imprinting is direct imprinting, which needs to imprint the most characteristic component of a microorganism. Direct imprinting can be classified into three main types, i.e., stamp imprinting, film imprinting (drop-coating imprinting, thin film imprinting, and imprinting with modified polymers) and sacrificial layer imprinting. A schematic of the procedures of these three methods is shown in Fig. 1.

\subsubsection{Stamp imprinting}

Stamp imprinting is a common imprinting method due to its simplicity and convenience. As shown in Fig. 1, firstly, the target analyte is spread on the surface of small stamp, and then the solvent is removed by different ways according to the different solvent types. The solvent without buffer solutions can be wiped off by drying the surface, while the solvent containing buffer solutions must be dislodged by spin coating; otherwise, crystallization of the buffer solutions will cover the template molecules. Afterward, the stamp is pressed onto the surface of the prepolymer. However, one of the most important parameters that must be optimized is the viscosity of the prepolymer. When the stamp is being pressed onto the surface of the prepolymer, the prepolymer must be soft enough to generate imprinted cavities. Meanwhile, the prepolymer can't be excessively soft; otherwise, the stamp may sink into the prepolymer and would be difficult to take out from the cured prepolymer.

Darder et al. [32] developed electrochemical sensors using sol-gel biohybrids as an active phase, and the preparation of algalbased hybrid materials is shown in Fig. 2(A). Scanning electron microscopy (SEM) and atomic force microscopy (AFM) results carried out with the Anabaena sol-gel material, showed that algae could be removed from the polymeric network, and leave traces that had the algae's peculiar three-dimensional shape. As shown in Fig. 2(B), using contact-less dielectric micro sensors, Ertl et al. [33] reported the development of a microfluidic biochip containing integrated MIPs, and continuously monitored viral contamination with high sensitivity and selectivity. The integration of MIPs was accomplished by pressing the virus stamp into the copolymer of vinylpyrrolidone and methacrylic acid, the copolymer was spincoated at a layer height of $200 \mathrm{~nm}$ on the device.
However, stamp imprinting is not suitable for very fragile template molecules, such as blood erythrocytes and sensitive protein [34]. Additionally, the selectivity of MIPs is greatly compromised for large and asymmetric template molecules because the analyte is difficult to capture in the same orientation as the template.

\subsubsection{Film imprinting}

With the development of microorganism imprinting, film imprinting has rapidly emerged, including drop-coating imprinting, thin film imprinting and imprinting with modified polymers. The drop-coating method can be used for imprinting very fragile biological samples, such as cells. A high-concentration prepolymer is spin-coated on the surface of the support vector, and one of the polymer monomers can be used as a solvent, so that no further dilution is required. After that, the template molecule is immediately dropped onto the polymerizing film. A few minutes later, the precipitated template molecule will leave an imprint trace on the membrane. Seifner et al. [34] use drop coating with erythrocytes as templates to yield polymer coatings with selective recognition sites towards red blood cells.

For the preparation of MIPs in the form of a thin film, a microorganism coated glass slide is pressed against a prepolymerized polymer film coated slide [24]. Cohen et al. [35] produced organically modified silica films by the sol-gel procedure (Fig. 2(C)), and used them to imprint whole cells of different microorganisms for devising a probe for concentrating and identifying microorganisms in water and other liquids. The microbes selected to test this procedure were gram-positive bacteria: Deinococcus radiodurans (D. radiodurans), Escherichia coli (E. coli), Sphaerotilus natans (S. natans) and Bacillus subtilis (B. subtilis). The high adsorption affinity of these films with each of the test microorganisms made them promising candidates for rapid and selective detection of these microorganisms in liquids.

Imprinting with modified polymers, which is similar to thin film imprinting, means there are some modified polymers to protect template when imprinting, for example, polymer brushes. As shown in Fig. 2(D), Zdyrko et al. [36] described an original approach for surface protein imprinting employing grafting of polymer brushes. The disadvantage of film imprinting is that the vast majority of the methods used to distinguish templates depend on size effects rather than surface chemical properties. Additionally, film imprinted can be used only for a sufficiently large template because the template needs to be thicker than the surrounding polymer film.

Table 1

Advantages, disadvantages and template molecules of various technologies and strategies of MIT for microorganism analysis.

\begin{tabular}{|c|c|c|c|c|c|}
\hline \multicolumn{2}{|c|}{ Imprinting methods } & \multirow{2}{*}{$\begin{array}{l}\text { Advantages } \\
\text { Easy operation; widely application }\end{array}$} & \multirow{2}{*}{$\begin{array}{l}\text { Disadvantages } \\
\text { Not suitable for some fragile } \\
\text { or large templates }\end{array}$} & \multirow{2}{*}{$\begin{array}{l}\text { Template molecules } \\
\text { From small molecules to } \\
\text { whole cells }\end{array}$} & \multirow{2}{*}{$\frac{\text { Ref. }}{[32]}$} \\
\hline $\begin{array}{l}\text { Direct } \\
\quad \text { imprinting }\end{array}$ & Stamp imprinting & & & & \\
\hline & Film imprinting & $\begin{array}{l}\text { Easy operation; suitable for fragile } \\
\text { samples }\end{array}$ & $\begin{array}{l}\text { Size effect is used to distinguish most of } \\
\text { samples, } \\
\text { rather than the surface chemistry, used for } \\
\text { large enough samples. }\end{array}$ & $\begin{array}{l}\text { Large samples and } \\
\text { fragile sample }\end{array}$ & [34] \\
\hline & $\begin{array}{l}\text { Sacrificial layers } \\
\text { method }\end{array}$ & $\begin{array}{l}\text { Aim at specific affinity between certain } \\
\text { non-polymeric materials and template }\end{array}$ & $\begin{array}{l}\text { Complicated operation; incompatible } \\
\text { relation between polymers and templates }\end{array}$ & $\begin{array}{l}\text { Template with specific } \\
\text { affinity } \\
\text { with some non-polymeric } \\
\text { materials }\end{array}$ & [37] \\
\hline \multirow[t]{3}{*}{$\begin{array}{l}\text { Indirect } \\
\text { imprinting }\end{array}$} & $\begin{array}{l}\text { Substructures } \\
\text { imprinting }\end{array}$ & $\begin{array}{l}\text { Epitope similar to natural antibody; } \\
\text { suitable for large template }\end{array}$ & $\begin{array}{l}\text { Hard discovery process } \\
\text { of epitope }\end{array}$ & Large template & [40] \\
\hline & Artificial template & $\begin{array}{l}\text { Use repeatedly; suitable for samples } \\
\text { which are not easy to operate }\end{array}$ & $\begin{array}{l}\text { Complicated operation; multiple imprinting } \\
\text { steps }\end{array}$ & Virus, dangerous templates & [42] \\
\hline & $\begin{array}{l}\text { Artificial antibody } \\
\text { replicas }\end{array}$ & $\begin{array}{l}\text { Suitable for large template; use } \\
\text { repeatedly }\end{array}$ & $\begin{array}{l}\text { Complicated operation; multiple } \\
\text { imprinting steps; require natural antibody }\end{array}$ & Large template & [45] \\
\hline
\end{tabular}




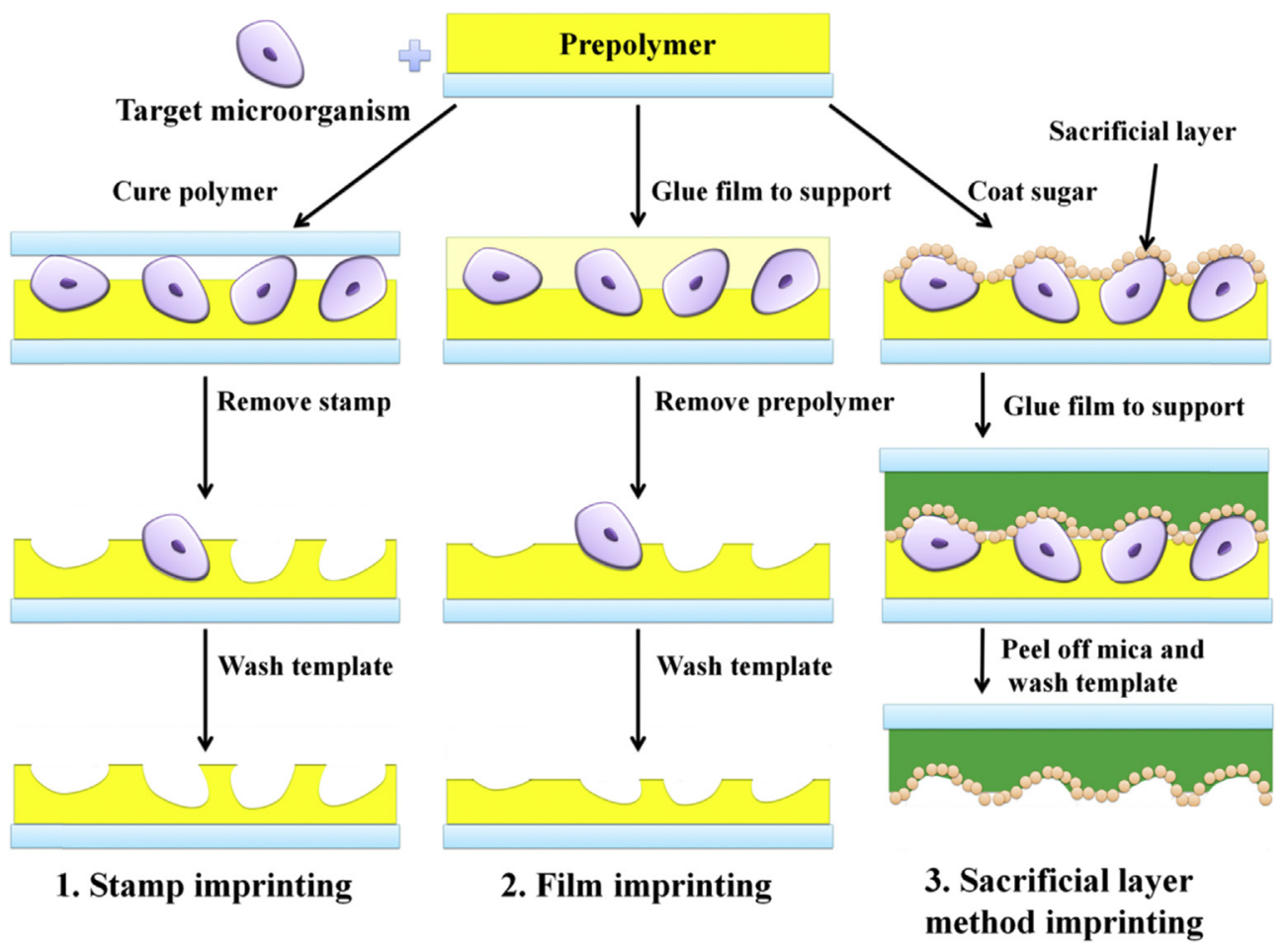

Fig. 1. Schematic procedures for three types of directing imprinting.
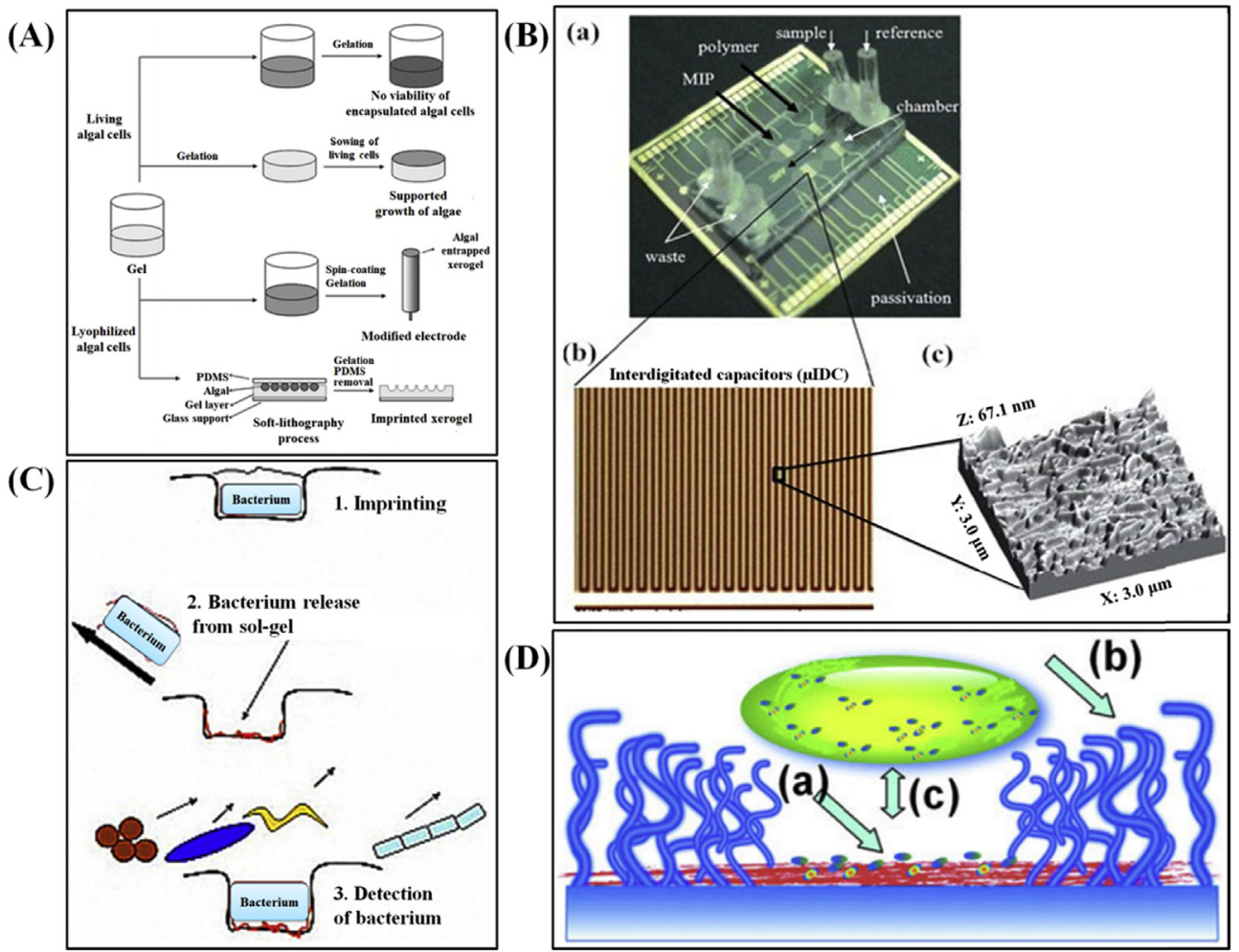

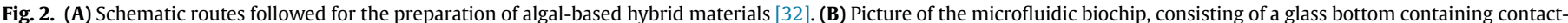

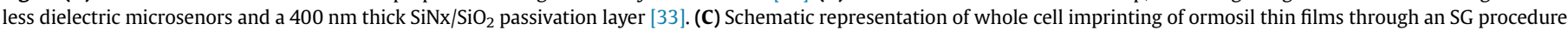

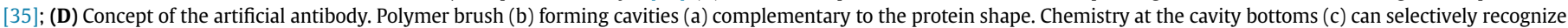
imprinted proteins [36]. 


\subsubsection{Sacrificial layer method imprinting}

The sacrificial layer method imprinting combines the advantages of surface imprinting for easy removal of the template and the advantages of integral imprinting to produce more binding sites. As shown in Fig. 1, this method is mainly achieved through the sol-gel process. We can see from the third way in Fig. 1, a sacrificial layer covalently bound to the formed polymer is added between the sample and the prepolymer, which can prevent the reaction between the sample and the polymer monomer and introduce new functional groups. Starosvetsky et al. [37] produced organically modified silica thin films by the sol-gel method. The thin films were imprinted with two bacterial strains as whole cells in order to develop an easy, fast and specific probe to detect and specifically identify these microorganisms when present in water samples. The films also showed high selectivity toward the imprinted template and were able to discriminate between two very close bacterial species (E. coli and S. typhimurium). The sacrificial layer method is convenient for the situation in which the template can react with the monomer; however, this method usually requires complicated operation such as preparation and washing of the sacrificial layer compared with film imprinting.

In addition to the above methods, there are also some other methods that can achieve direct imprinting, such as orientation imprinting [38] and polymer microbes [39] etc.

\subsection{Indirect imprinting}

Direct imprinting is a convenient method that is widely applied in microorganism imprinting. However, the selectivity of direct imprinting is not suitable for some target microorganisms, such as cells, unstable molecules and some viruses, which are large in size, structurally complex, have poor stability in organic solvents and thus are danger. If the processing procedures are overly difficult, direct imprinting cannot be easily achieved. Indirect imprinting does not use the target analyte directly, but rather uses other molecules, part of the target analyte or artificial antibody replicas that can achieve similar selectivity to direct imprinting.

\subsubsection{Substructure imprinting}

A simple way to achieve the selectivity for a biomolecule is to imprint the most characteristic structure of this molecule, which is called substructure imprinting. This method is analogous to antigen recognition by antibody, where an "epitope" of the immunogenic protein is the binding site of antibody, rather than the whole protein. Large imprinted sites can be seen as general nanopores that would have more interactions with a series of other small peptides, which may hinder or frustrate imprinting effect, thus reducing selectivity. Therefore, small biomolecule tend to make better imprinting sites. Khan et al. [40] presented a novel MIP for the indirect detection of bacteria by targeting an outer membrane protein on a disposable device. They selected Protein A (PA) as a representative protein of the outer surface of Staphylococcus aureus. The MIP was assembled directly on a film of single-walled carbon nanotubes (SWCNTs) and placed on screen-printed electrodes, and the MIP material was produced by electro polymerizing 3aminophenol in the presence of PA using cyclic voltammetry $(\mathrm{CV})$. The proteins entrapped in the polymeric backbone were digested by the action of the proteolytic activity of proteinase $\mathrm{K}$ and then washed away to create vacant sites. The detection limit of these MIP-based sensors was approximately $0.60 \mathrm{nM}$ in MES buffer. The sensor performance was also tested to check for any effects from inorganic ions in tap water. The detection limit was $16.83 \mathrm{nM}$, with a recovery rate of $91.1 \pm 6.6 \%$. The sensor described in this work is a potential tool for screening PA from Staphylococcus aureus on-site.
In regard to the production of MIP for large biomolecules, due to the large size of the target biomolecules, the obtained MIP often lacks binding sites within the polymer interior. Substructure imprinting as an alternative strategy needs to be developed to limit recognition to the surface of the polymer [41]. The disadvantage of substructure imprinting is that the substructure that appears on the surface of the target analyte should be confirmed first. However, this is usually not apparent and as the synthesis of substructures is not easy, this is hard to realize in practice.

\subsubsection{Artificial template imprinting}

For very complex templates, such as a whole cell, the cell mass and volume may fluctuate greatly. Furthermore, if the template microorganism is pathogenic or unfit for culturing, the investigator may wish to avoid touching it as much as possible. Fortunately, the main advantage of the artificial template imprinting approach is that artificial templating has a very high reproducibility, and its artificial templates can be used repeatedly to replace the real microorganism. Fig. 3(A) [42] schematically depicts the preparation process for artificial template. Firstly, the natural template is imprinted onto a soft polymer. After removing the template, the remaining holes are filled with another polymer, and the second polymer becomes a man-made template. Reusable natural template replica can be obtained by separating the two polymers. Sykora et al. [43] used a virus-like particle (VLP) of Norovirus (NorVLP) from the predominant genotype II strain 4 (GII.4), and demonstrated that a virus recognition nanomaterial could be prepared by using VLPs as a safe substitute for the imprinting of a human pathogenic NorVLP. First, they immobilized the template virus on amino silica nanoparticles (SNP) using glutaraldehyde as cross linker. Next, they used silane self-assembly and polycondensation reactions to form the organosilica recognition layer. Finally, the template was then removed to free the imprinted sites. However, the preparation of an artificial template is difficult and time-consuming.

\subsubsection{Artificial antibody replicas}

Natural antibodies used as biorecognition elements suffer from numerous shortcomings, such as expensive long-term processing, limited chemical or environmental stability [44]. Artificial antibody replicas based on molecular imprinting are an attractive alternative to naturally antibodies $[45,46]$, and their mechanical and chemical robustness are ideal. Artificial antibody replicas can also be produced by self-assembly processes without the need for timeconsuming complex synthesis. Additionally, the monomeric building blocks used are often readily available by mass production [47]. Artificial antibody method is based on natural antibodies and the imprinting matrix has a similar epitope. First, polymer particles are prepolymerized and precipitated in the presence of the antibody. After removing the natural antibodies, the nanoparticles generate a structure complementary to the template, which can be repeatedly used. And then these polymer nanoparticles are affixed to a glass plate, these glass plates were used for secondary imprinting to obtain imprinted polymer films of antibodies on the surface of glass plates, which is similar to stamp imprinting.

Hu et al. [45] investigated the role of the aromatic interactions in target recognition abilities of artificial antibodies. They employed refractive index sensitivity of plasmonic nanostructures as a transduction platform for monitoring various steps in the imprinting process, and quantified the target recognition abilities of the artificial antibodies (Fig. 3(B)). The sensitivity of the artificial antibodies with aromatic interactions exhibited protein-dependent enhancements. Selectivity and sensitivity enhancement due to the presence of aromatic groups in imprinted polymer matrix was 


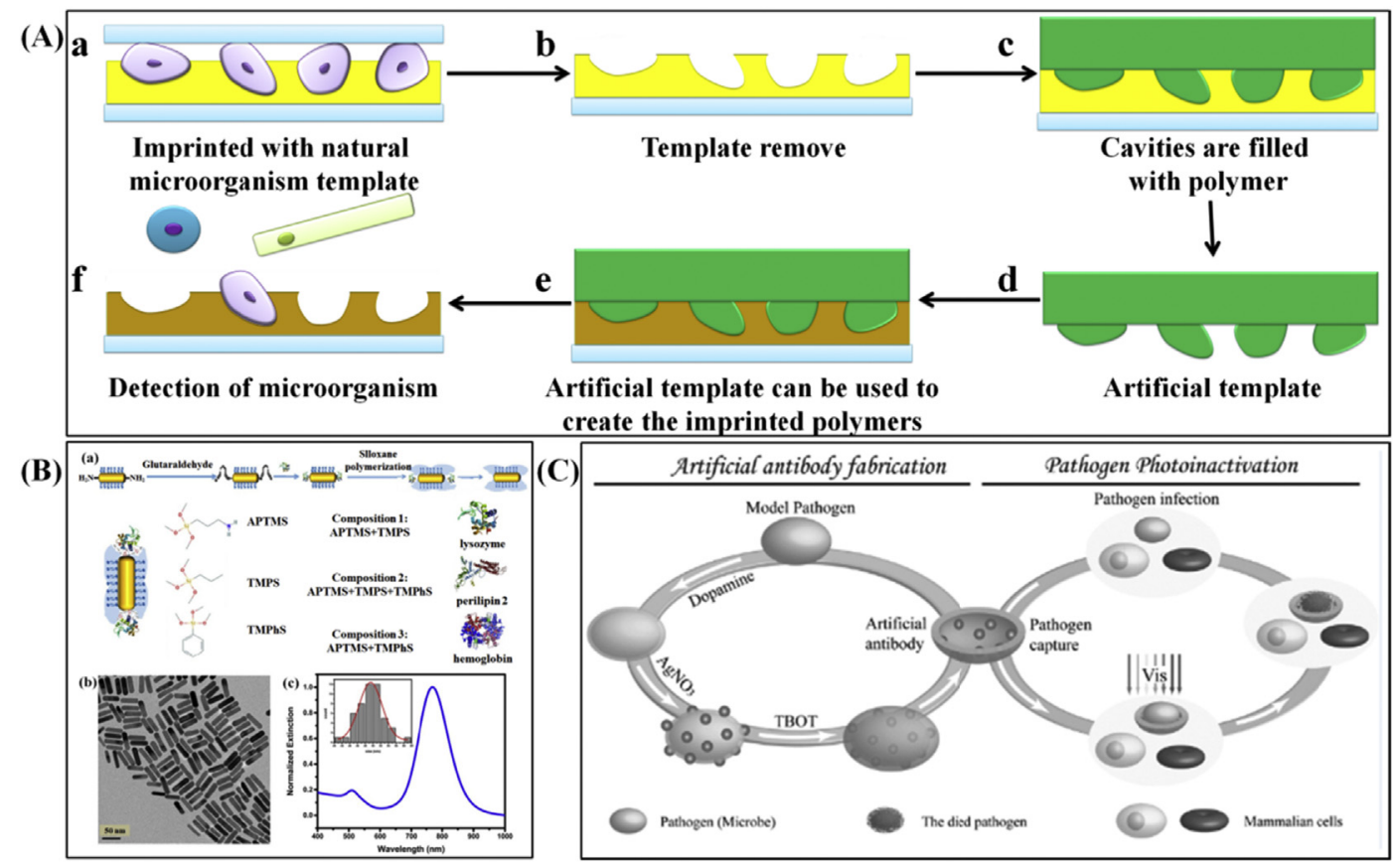

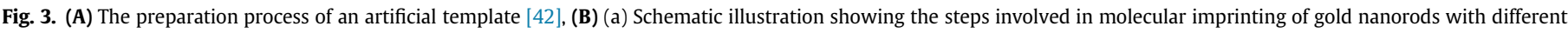

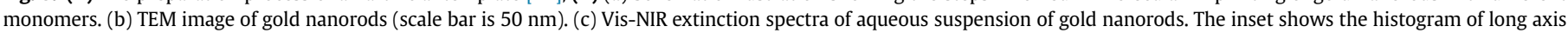

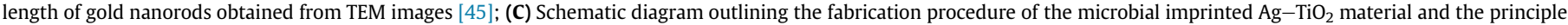
of microbial inactivation by the artificial antibody [48].

found to be higher for target proteins with higher aromatic amino acid content.

By taking advantage of imprinting technology, Zhang et al. [48] fabricated artificial antibody-microbial imprinted $\mathrm{Ag}-\mathrm{TiO}_{2}$ materials for microbial inactivation. In their designed artificial antibody, the $\mathrm{Ag}-\mathrm{TiO}_{2}$ composite was endowed with pathogen recognition ability for the sake of lowering the toxic side effect. As presented in Fig. 3(C), the artificial antibody was fabricated in a facile and green method. Due to the induced shape and size targeting elements, the imprinted materials can bind specifically to microbes by matching their shape and size, and can kill them under visible light irradiation with very low cytotoxicity toward mammalian cells. However, the operating processes of this method are more sophisticated and require specific antibodies against the analyte.

\section{Analytical detection methods coupled with MIP systems}

\subsection{Fluorescence biosensor}

Fluorescence biosensors are an analytical device that uses immobilized biosensor materials such as enzymes, antigens/antibodies, aptamers, nucleic acids, liposomes, cells and microorganisms, as recognition elements and uses fluorescence signals as a signaling unit $[49,50]$. As the fluorescent biosensor has a nondestructive mode of operation, high signal generation and reading speed, fluorescence detection technology has become the most commonly used method in the field of bioanalysis [51,52], even in tumor diagnosis [53]. These biosensors can detect microorganisms rapidly based on fluorescence, thus the incorporation of fluorescence into molecularly imprinted sensors has been widely researched.

Traditional fluorescent labels, for instance organic dyes, are often easily photobleached and exhibit narrow absorption and broad emission spectra with long tails, thus resulting in low detection sensitivity. Fluorescent nanoparticles can overcome the shortcomings of traditional fluorescent labels, achieve strong fluorescence signals, greatly improve the sensitivity, and function in a wide range of applications [54-56]. Liu et al. [57] prepared a novel fluorescent conjugated polymer nanoparticle (NP), and these materials would have good potential application as a suitable fluorescent probe for targeted cancer cell imaging. They modified poly ( fluorene-alt-benzothiadiazole) (PFBT) with phenylboronic acid (PBA) groups as binding sites for sialic acid (SA) molecules, and the SA molecules were easily removed from the NP surface by adjusting the surrounding $\mathrm{pH}$ followed by dialysis. A cell imaging assay clearly indicated that SA-imprinted NPs can selectively bind with SA overexpressed in DU 145 cancer cells (Fig. 4 (A)).

Liang et al. [58] designed a fluorescent sensor based on virusmolecular imprinted polymers (virus-MIPs) for specific recognition and highly sensitive detection of Japanese encephalitis virus (JEV). The virus-MIPs were anchored on the surface of silica microspheres modified with a fluorescent dye, pyrene-1-carboxaldehyde (PC). With the virus acting as an energy donor and PC acting as the energy acceptor, the fluorescence intensity of PC could be enhanced by the principle of fluorescence resonance energy transfer (FRET). The enhanced fluorescence intensity was proportional to the concentration of virus in the range of 24-960 pM, with a limit of detection (LOD) of $9.6 \mathrm{pM}$, and the relative standard deviation was $1.99 \%$. As presented in Fig. 4(B), Chen et al. [59] developed an electrochemiluminescence (ECL) biosensor for Escherichia coli 0157:H7 quantitative detection based on a polydopamine (PDA) surface imprinted polymer (SIP) and nitrogen-doped graphene quantum dots (N-GQDs). The uniform PDA SIP film for E. coli 0157:H7 was established successfully with a facile route. The dopamine and target bacteria were electropolymerized directly on the electrode. After removal of the E. coli 0157:H7 template, the established PDA SIP can selectively recognize E. coli 0157:H7. The linear relationships between the ECL intensity and E. coli $0157: H 7$ concentrations were obtained from $10^{1}$ colony-forming units (CFU) $\mathrm{mL}^{-1}$ to $10^{7} \mathrm{CFU} \mathrm{mL}$ with a limit of detection of $8 \mathrm{CFU} \mathrm{mL} \mathrm{m}^{-1}$. 

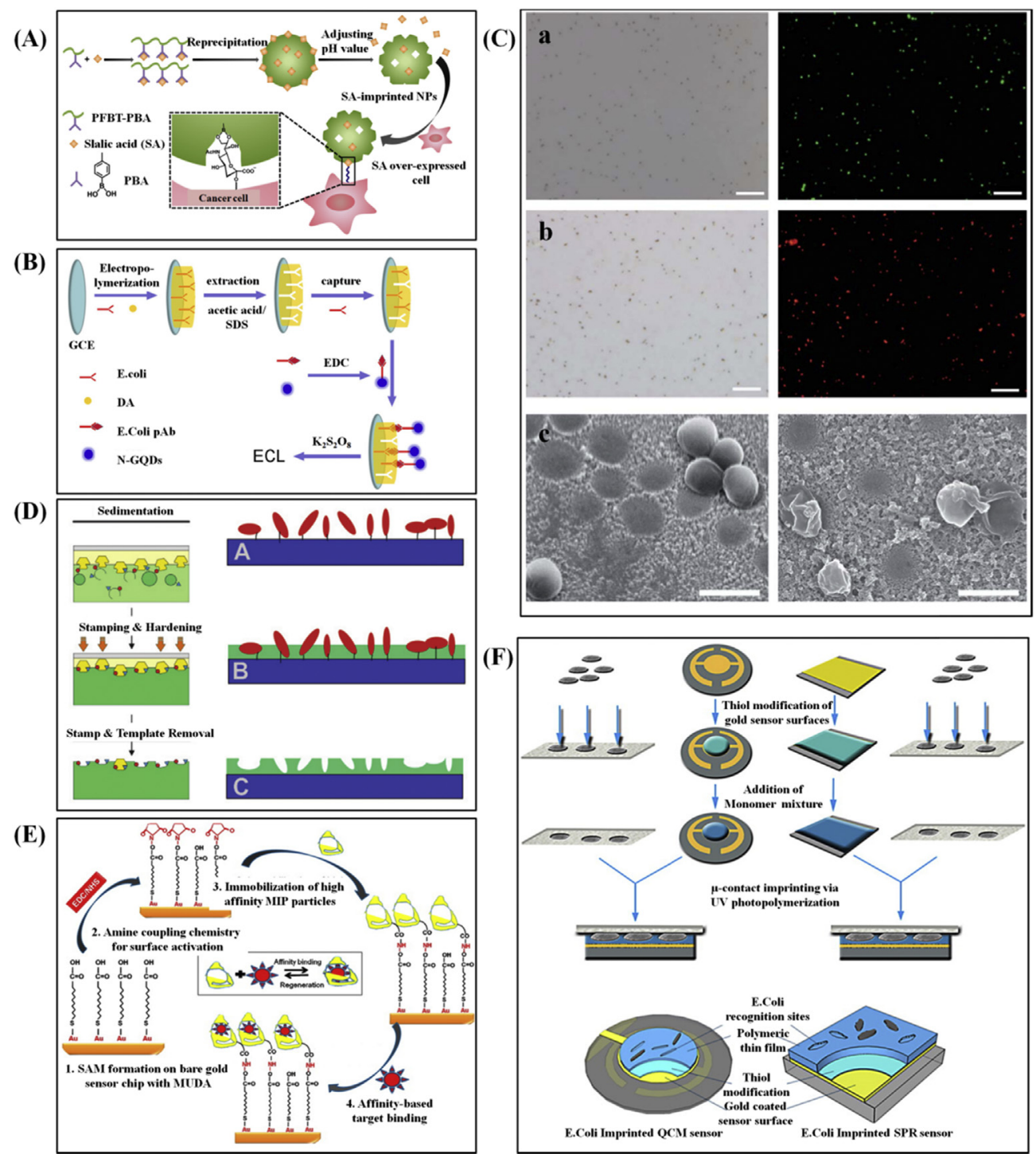

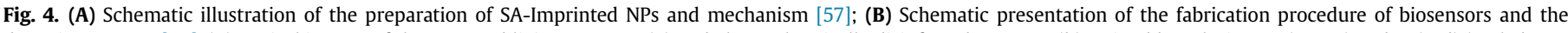

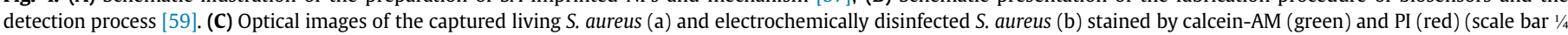

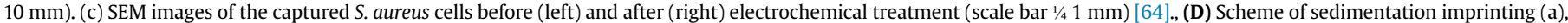

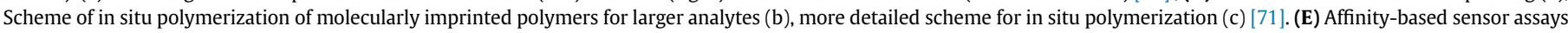
for virus detection [78]. (F) Schematic representation of microcontact imprinted SPR and QCM sensor surfaces [79].

\subsection{Electrochemical biosensor}

Electrochemical sensors consist of a sensitive membrane that identifies the analyte and converts the biomass into an electrical signal [60]. There are two types of sensors, namely, current-type sensors and potential-type sensors. Current-type sensors are based on the detection of biological recognition or chemically reactive substances in the chemical reaction, which provide the driving force and detect current changes over time through the fixed electrode potential of an active electron transfer reaction. The potential-type sensor converts the biometric reaction into an electrical signal, this signal is proportional to the logarithm of the concentration of the active substance produced or consumed during the biometric reaction. Biosensors incorporate trace biological samples, such as functional proteins, nucleic acids, cell organelles, or even whole living cells. The biological samples are immobilized on the surface of a physicochemical transducer, and the transducer is able to transfer specific interactions of the immobilized biological samples with its corresponding binding analyte into measurable, concentration-dependent electrical signals [61].

Electrochemical biosensors combine selective biochemical recognition with the high sensitivity of electrochemical detection to acquire practical availability. The positive features of electrochemical biosensors are high sensitivity, ease of miniaturization, and cost-effectiveness. Therefore, they are widely used in biosensor field [62]. Namvar et al. [63] provided a proof of concept for the fabrication of microbial imprinted films from conducting polymer composite membranes for the detection of Bacillus subtilis endospores. The imprinted films were submerged in spore suspensions to absorb the spores and were heat activated at $70{ }^{\circ} \mathrm{C}$ for $10 \mathrm{~min}$ prior to transferring to an electrochemical cell containing germination activators and it was possible to detect $10^{2} \mathrm{CFU} / \mathrm{mL}$ using the assay format. Zhang et al. [64] manufactured a cell imprinted with artificial antibodies to set up a sandwich enzyme-linked immunosorbent assay (ELISA) for pathogen detection. The constructed ELISA could be used for target pathogen detection with high 
sensitivity and selectivity. The captured antibody can disinfect pathogens in situ through an electrochemical technique, and the influence of electrochemical treatment is shown in Fig. 4(C). In addition, the detection limit was approximately $500 \mathrm{CFU} / \mathrm{mL}$, which is much lower than that of traditional ELISA methods.

\subsection{Piezoelectric biosensor}

Quartz crystal resonators are very steady and accurate oscillators that have been successfully used for frequency measurements in electronic devices, but also form the basis for quartz crystal microbalance (QCM) sensors. Piezoelectric immunosensors use QCM as a signal conversion element, and transfer the mass change produced by the binding of the antibody to the bacteria into a frequency signal. QCM sensors are composed of a thin quartz disc with electrodes plated on it. When an oscillating electric field is applied across the disc, an acoustic wave with a certain resonance frequency is induced. The disc can be coated with a sensing layer according to the analyte to be detected. The change in mass, which occurs when the analyte accumulates on the surface of the disc leads to a change in resonance frequency, and the resonance frequency change can then directly correlate with biomolecular interactions. QCM sensors offer advantages such as high sensitivity, real-time output, simplicity of use, and the required instruments are inexpensive and simple [65]. In most electrochemical experiments, mass changes arise as material is deposited or lost from the working electrode. It is meaningful to monitor those changes synchronously with the electrochemical response [66].

Many possible applications for QCM systems have been described in the fields of food [67], environment [68], and clinic analysis [69], etc. Samardzic et al. [70] developed a sensor based on a MIP coated QCM as the mass sensitive transducer. They were able to reach a limit of detection of $1.6^{*} \times 10^{8}$ cells $/ \mathrm{mL}$ within a few minutes. Then, Schnettelker et al. [71] presented an approach to synthesize MIPs for E. coli in situ on a suitable transducer surface. The MIP layer, which is generated directly on a QCM surface, showed enhanced selectivity towards E.coli and provided sensor responses within $3 \mathrm{~min}$. This technique can inherently be generalized, and thus it can be applied to a wide range of analytes, as is shown in Fig. 4(D).

QCM is a high resolution mass sensitive transducer that can measure a change in the mass of a target analyte by monitoring variations in the vibration frequency of the quartz crystal in real time $[72,73]$. The combination of the QCM technique with MIPs provides label-free, selective, sensitive, low cost, simple and stable detection systems [74].

\subsection{SPR biosensor}

Over the last twenty years, SPR technique for sensing application has attracted much attention due to their compact design, low cost and label-free sensing, etc [75]. The SPR sensor technology takes advantage of surface plasmon waves, which are electromagnetic waves that can be excited by light on gold sensor surfaces. When p-polarized light is incident on a metal-dielectric interface in the Kretschmann configuration at an angle greater than the critical angle, due to matching of wave vectors of evanescent wave (occurs owing to total internal reflection) and surface plasmon wave, some fraction of energy of the incident light is transferred to the surface plasmons for its excitation which leads to the surface plasmon resonance phenomenon $[76,77]$.

In recent years, the SPR technique along with MIPs has been used for the detection of various analytes. Altintas et al. [78] developed an MIP targeting the bacteriophage MS2 as a template using a novel solid-phase synthesis method (Fig. 4(E)). A high affinity between the target and the artificial ligand was found, and a regenerative MIP-based virus detection experiment was investigated using a new SPR biosensor that provides an alternative technology for the concrete detection and removal of waterborne viruses. In addition, Denizli et al. [79] summarized the QCM and SPR, as shown in Fig. 4(F), with a microcontact imprinting technique with supplementary cavities for chemical recognition ability against $E$. coli were obtained on the sensor surface.

Additionally, as listed in Table 2 [57,58,62,63,78,80-86], we summarized different biosensors for microorganism detection by coupling with various MIP systems.

\section{Application of microbiological imprinting}

\subsection{Detection and quantification of bacteria}

Before the occurrence of serious safety issues, detecting the presence of microorganisms in both unprocessed and final products is extremely significant. However, bacteria and viruses are very small microorganisms (in the range of $1-3 \mu \mathrm{m}$ and $30-700 \mathrm{~nm}$, respectively) and conventional bacterial identification and counting methods are time-consuming and usually require multistep sample pretreatments before testing $[83,87]$. As already shown in previous studies, different types of microorganisms can also be detected and quantified by methods based on MIPs.

Yilmaz et al. [79] selected E. coli as a model bacteria and developed a new label-free rapid and selective detection method via micro contact imprinting. The whole cells were imprinted on both optical and mass sensitive devices for the rapid detection of bacteria from water sources. The amino acid based recognition element, N-methacryloyl-l-histidine methylester (a polymerizable form of histidine) was used in their study to obtain similar recognition as in natural antibodies. Besides, QCM MIP-based biosensors have been used for detection of the plant pathogen Tobacco mosaic virus at $100 \mathrm{ng} / \mathrm{mL}$ [88].

Table 2

Summary of different biosensors coupled with MIP systems for microorganism detection.

\begin{tabular}{|c|c|c|c|c|}
\hline Target microorganism & Sensor type & Sensitivity & Response time & Ref. \\
\hline Cancer cells & Fluorescence & $0.071 \mathrm{mg} / \mathrm{mL}$ & $30 \mathrm{~min}$ & [80] \\
\hline Japanese encephalitis virus & Fluorescence & $9.6 \mathrm{pM}$ & $40 \mathrm{~min}$ & [57] \\
\hline E. coli $0157: H 7$ & Fluorescence & $8 \mathrm{CFU} / \mathrm{mL}$ & - & [58] \\
\hline Bacillus endospores & Electrochemical & $10^{2} \mathrm{CFU} / \mathrm{mL}$ & - & [62] \\
\hline Staphylococcus aureus & Electrochemical & $500 \mathrm{CFU} / \mathrm{mL}$ & - & [63] \\
\hline Prostate Specific Antigen & Electrochemical & $2.0 \mathrm{ng} / \mathrm{mL}$ & - & [81] \\
\hline E.coli & QCM & $3.72 \times 10^{5} \mathrm{CFU} / \mathrm{mL}$ & $56 \mathrm{~s}$ & [78] \\
\hline Campylobacter fetus & QCM & $10^{3} \mathrm{CFU} / \mathrm{mL}$ & $170 \mathrm{~min}$ & [82] \\
\hline Tobacco mosaic virus & QCM & $100 \mathrm{ng} / \mathrm{mL}$ & $30 \mathrm{~min}$ & [83] \\
\hline Cowpea mosaic virus & SPR & $12.5 \mu \mathrm{g} / \mathrm{mL}$ & - & [84] \\
\hline Fusarium culmorum & SPR & $0.06 \mathrm{pg}$ & - & [85] \\
\hline Puccinia striiformis & SPR & $10^{4} \mathrm{CFU} / \mathrm{mL}$ & $45 \mathrm{~min}$ & [86] \\
\hline
\end{tabular}


Borovicka et al. [89] produced a colloid analog of antibodies, which recognize the shape of target cells, by fabricating silica shell fragments templating the cell surface. To form core-shell particles, as shown in Fig. 5(A), they created such shell fragments by depositing silica through a sol-gel process onto the surface of target cells, followed by their fragmentation via mild ultrasonic treatment and further removal of the cells' cores through a bleaching process. After laser irradiation, the localized heating around the AuNPs kills the microbial cells of matching shape. They confirmed the cell shape-specific killing by photothermal colloid antibodies in a mixture of two bacterial cultures of different cell shape and size. Tokonami et al. [90] developed a label-free and selective $E$. coli identification film by surface imprinting the bacteria on the surface of overoxidized polypyrrole, which could detect bacterial within the range of $10^{3}-10^{9} \mathrm{CFU} / \mathrm{mL}$ within $3 \mathrm{~min}$, as shown in Fig. 5(B).

\subsection{Identification of bacterial species}

According to bacterial surface chemical structure, bacteria are generally classified into two groups: gram-positive and gramnegative bacteria. Cell culture remains a standard technique for identifying bacterial species; however, it usually requires $24-48 \mathrm{~h}$, depending on the growth speed of the target bacterium [91]. Tokonami et al. [91] successfully developed bacterial templates on the surface of an overoxidized polypyrrole film using both gramnegative and gram-positive bacteria, in which bacterial surface chemical structures are exactly transferred at the molecular level. The preparation for the bacterial template on the polymer layer is shown in Fig. 5(C). The unique combination of MIPs with bacterial cavities and the dielectrophoresis technique allowed detection of bacterial in a label-free format within $5 \mathrm{~min}$, without any bacterial
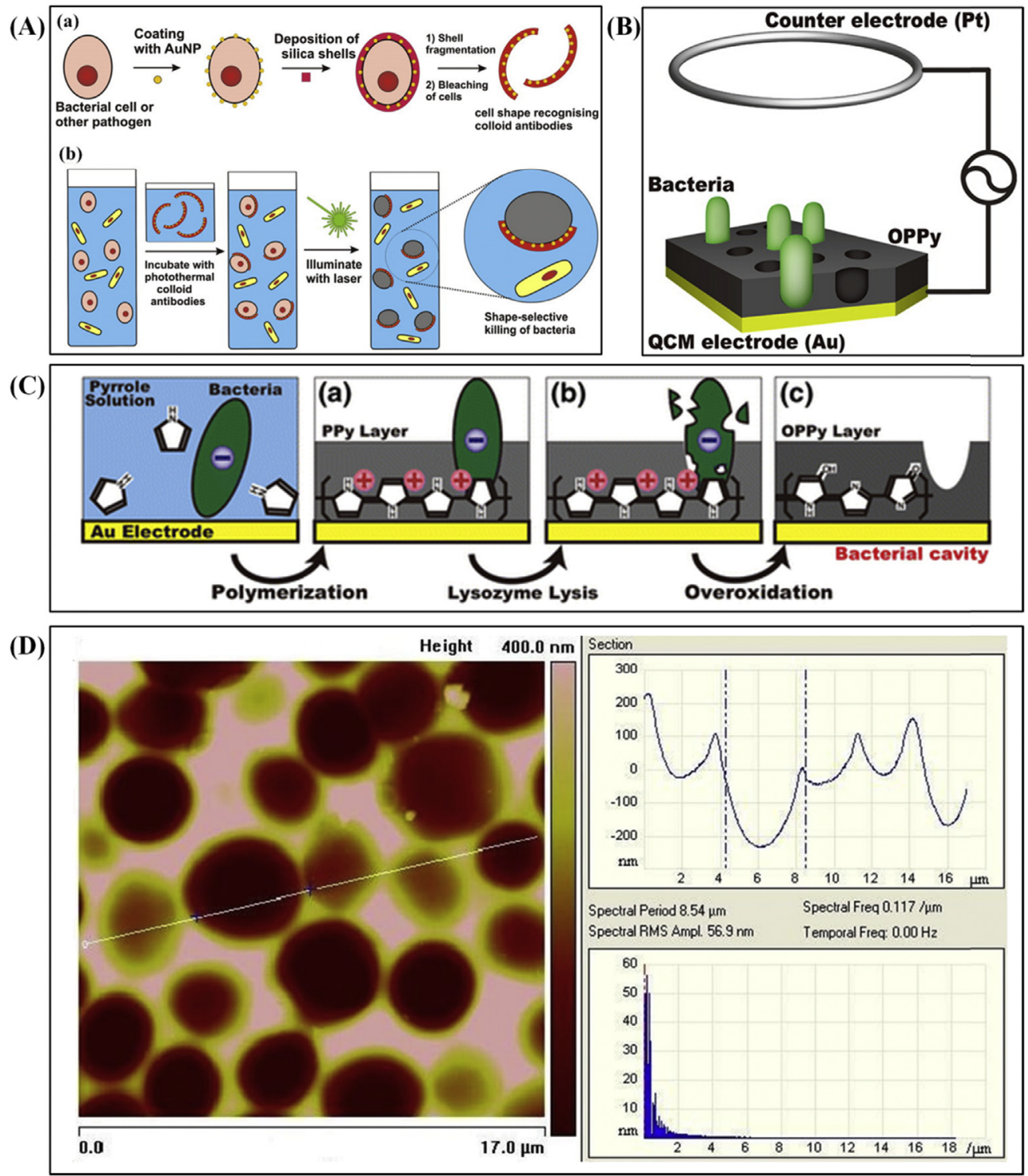

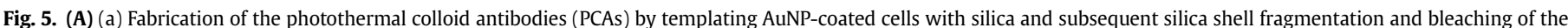

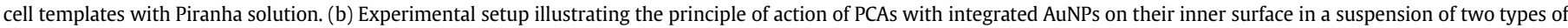

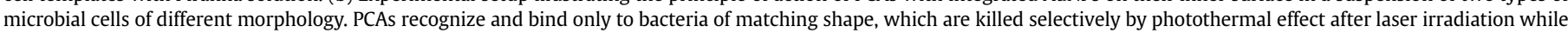

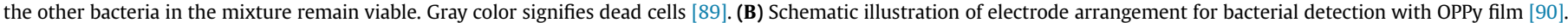

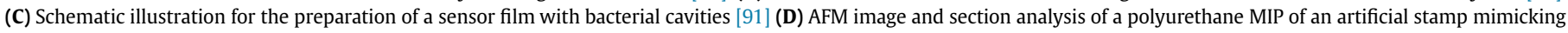
growing yeast cells showing grown species and some buds [92]. 
pretreatment. And it has achieved specific identification of $E$. coli, $P$. aeruginosa, $B$. subtilis, and $S$. aureus via precise transfer of the bacterial surface structure to the OPPy film.

\subsection{Determination of yeast growth status}

As baker's yeast has different stages of growth during its reproductive cycle, the size and shape of the cells changes, but the chemistry on their surface remains essentially constant. However, the individual growth stages can be distinguished by the mass sensitive QCM detecting the weight of the microorganism.

Seidler et al. [92] presented an effective measuring system based on a 4-electrode QCM and adapted it in liquid phase measurements. Surface imprinting with different growth stages of $S$. cerevisiae finally led to a biomimetic chemosensor appropriate to monitor the growth development of this significant microorganism. Fig. 5(D) shows an AFM image of the polyurethane-layer sensitive to cells of this growth stage generated by artificial stamp. Molecular imprinting with such master stamps can mimic native yeast cells in $\mathrm{G}_{0}$ and early $\mathrm{S}$ phase, indicating that different growth stages can be distinguished by the sensors, which is potentially interesting for monitoring fermentation processes.

\section{Conclusions}

In this review, the current status of MIT for microorganism analysis is summarized, overviewing different imprinting methods for microorganisms, highlighting sensing analytical methods coupled with MIT, and discussing representative applications of microorganism imprinting. Although developed methods may also be used as a universal protocol to imprint microorganisms for their sensing detection by different kind of sensors, and many advances are promising, microorganism imprinting still faces some challenges. For instance, the free binding of a microorganism analyte to a molecular cavity is essential for the effective application of the MIPs materials to either separation or sensing. Additionally, variation in the morphology and mass of microorganisms is not an easy question to solve. Surface imprinting of microorganisms is an effective method that can improve their binding efficiency, but still urgently requires improvement. The adsorption of microorganism on sensor surfaces allows the adsorbed layer to be used as a "stamp" for the manufacture of imprinted thin layers materials, and the template microorganism can be immobilized in a particular orientation. Accordingly, the specificity and affinity of the imprinted analytes can be substantially ameliorated. As we all know, the detection of microorganisms at very low concentrations in complex matrices is a challenging task, especially when aiming for point-ofcare monitoring. Therefore, higher sensitivity and higher selectivity are desirable, which requires to ingeniously devise/synthesize superior MIPs for microorganism with high specificity accompanying with rational coupling to sensing technologies.

The remaining challenges also bring out promising opportunities and trends in MIT for microorganism analysis. Miniaturization of the techniques and devices is probably a restriction point when attempting integration of the microorganism imprinting systems as a path to further improve analytical performance. Miniaturized separation techniques such as CEC, micro-LC, capillary-LC and nano-LC have become popular in recent decades and indicate a good alternative to conventionally and commonly employed chromatographic approaches. Besides, these techniques furnish higher separation efficiency, shorter analysis time and rapid optimization of experimental conditions. The realization of more portable devices, with a reduction in the logistical challenges, is also a result of miniaturization [93]. Future trends in microorganism analysis will continue, particularly with developments on increasing the stability, selectivity, and cost-effectiveness of MIPs and novel integrated devices, which will not only lead to applications in microorganism analysis and viruses-caused diseases therapy, but also greatly enrich the research connotations of MIT.

\section{Acknowledgments}

This work was financially supported by the National Natural Science Foundation of China (31701705, 31671823, 21477160, 21575159), Hong Kong Scholars Program (XJ2017060), Shanxi Province Agricultural Science and Technology Innovation and Key Project (2016NY-181), Key Laboratory of Coastal Environmental Processes and Ecological Remediation (2018KFJJ01) and Fundamental Research Funds for the Central Universities in China (GK201803084).

\section{References}

[1] T. Vincent, R. Agnès, R. Yoann, L. Thierry, Ligands for label-free detection of whole bacteria on biosensors: a review, TrAC Trends Anal. Chem. 79 (2016) $71-79$.

[2] R.N. Strange, P.R. Scott, Plant disease: a threat to global food security, Annu. Rev. Phytopathol. 43 (2005) 83-116.

[3] E.S. Robert, A.C. Matthew, A Survey of the 2010 Quartz crystal microbalance literature, Mol. Recognit. 25 (2012) 451-473.

[4] L.R. Ramon, T. Pol, C. Sophie, L.C. Jose, On-line bacteriological detection in water, Trends Anal. Chem. 44 (2013) 46-57.

[5] D.G. Newell, M. Koopmans, L. Verhoef, E. Duizer, A. Aidara-Kane, H. Sprong, M. Opsteegh, M. Langelaar, J. Threfall, F. Scheutz, J. Giessen, H. Kruse, Foodborne diseases-the challenges of 20 years ago still persist while new ones continue to emerge, Int. J. Food Microbiol. 139 (2010) S3-S15.

[6] R.L. Buchanan, L.G.M. Gorris, M.M. Hayman, T.C. Jackson, R.C. Whiting, A review of Listeria monocytogenes: an update on outbreaks, virulence, doseresponse, ecology, and risk assessments, Food Control 75 (2017) 1-13.

[7] P.D. Skottrup, M. Nicolaisen, A.F. Justesen, Towards on-site pathogen detection using antibody-based sensors, Biosens. Bioelectron. 24 (2008) 339-348.

[8] E. Parra, F. Segura, J. Tijero, I. Pons, M.M. Nogueras, Development of a real-time PCR for Bartonella spp. detection, a current emerging microorganism, Mol. Cell. Probes 32 (2017) 55-59.

[9] S. Ku, T. Kreke, E. Ximenes, K. Foster, X. Liu, C.J. Gilpin, M.R. Ladisch, Protein particulate retention and microorganism recovery for rapid detection of Salmonella, Biotechnol. Prog. 33 (2017) 687-695.

[10] G. Ertürk, R. Lood, Bacteriophages as biorecognition elements in capacitive biosensors: phage and host bacteria detection, Sens. Actuators B 258 (2018) $535-543$.

[11] J. Ashley, X. Feng, A. Halder, T. Zhou, Y. Sun, Dispersive solid-phase imprinting of proteins for the production of plastic antibodies, Chem. Commun. 54 (2018) 3355-3358.

[12] L.X. Chen, S.F. Xu, J.H. Li, Recent advances in molecular imprinting technology: current status, challenges and highlighted applications, Chem. Soc. Rev. 40 (2011) 2922-2942.

[13] M. Hasanzadeh, N. Shadjou, M.D.L. Guardia, Cytosensing of cancer cells using antibody-based molecular imprinting: a short-review, TrAC Trends Anal. Chem. 99 (2018) 129-134.

[14] Q. Yang, J.H. Li, X.Y. Wang, H.L. Peng, H. Xiong, L.X. Chen, Strategies of molecular imprinting-based fluorescence sensors for chemical and biological analysis, Biosens. Bioelectron. 112 (2018) 54-71.

[15] D. Bitas, V. Samanidou, Molecularly imprinted polymers as extracting media for the chromatographic determination of antibiotics in milk, Molecules 23 (2018) 316.

[16] S. Ncube, L. Madikizela, E. Cukrowska, L. Chimuka, Recent advances in the adsorbents for isolation of polycyclic aromatic hydrocarbons (PAHs) from environmental sample solutions, TrAC Trends Anal. Chem. 99 (2018) $101-116$.

[17] A.G. Ayankojo, J. Reut, R. Boroznjak, A. Öpik, V. Syritski, Molecularly imprinted poly(meta-phenylenediamine) based QCM sensor for detecting Amoxicillin, Sens. Actuators B 258 (2018) 766-774.

[18] M.F. Jia, Z. Zhang, J.H. Li, H.J. Shao, L.X. Chen, X.B. Yang, A molecular imprinting fluorescence sensor based on quantum dots and a mesoporous structure for selective and sensitive detection of 2,4-dichlorophenoxyacetic acid, Sens. Actuators B 252 (2017) 934-943.

[19] B.H. Liu, G.M. Han, Z.P. Zhang, R.Y. Liu, C.L. Jiang, S.H. Wang M.Y. Han, Shell thickness-dependent Raman enhancement for rapid identification and detection of pesticide residues at fruit peels, Anal. Chem. 84 (2012) 255-261.

[20] J.P. Fan, J.X. Yu, X.M. Yang, X.H. Zhang, T.T. Yuan, Preparation, characterization, and application of multiple stimuli-responsive rattle-type magnetic hollow molecular imprinted poly (ionic liquids) nanospheres ( $\mathrm{Fe}_{3} \mathrm{O}_{4} @$ void@PILMIP) for specific recognition of protein, Chem. Eng. J. 337 (2018) 722-732. 
[21] Z. Zhang, J.H. Li, X.Y. Wang, D.Z. Shen, L.X. Chen, Quantum dots based mesoporous structured imprinting microspheres for the sensitive fluorescent detection of phycocyanin, ACS Appl. Mater. Interfaces 7 (2015) 9118-9127.

[22] H. Oliver, F.L. Dickert, Selective microorganism detection with cell surface imprinted polymers, Adv. Mater. 13 (2001) 1480-1483.

[23] E.S. Redeker, K. Eersels, O. Akkermans, J. Royakkers, S. Dyson, K. Nurekeyeva, B. Ferrando, P. Cornelis, M. Peeters, P. Wagner, H. Dilien, B. Grinsven, T.J. Cleij, Biomimetic bacterial identification platform based on thermal wave transport analysis (TWTA) through surface-imprinted polymers, ACS Infect. Dis. 3 (2017) 388-397.

[24] M.T. Dulay, N. Zaman, D. Jaramillo, A.C. Mody, R.N. Zare, Pathogen-imprinted organosiloxane polymers as selective biosensors for the detection of targeted E. coli, C 4 (2018) 29.

[25] L.X. Chen, X.Y. Wang, W.H. Lu, X.Q. Wu, J.H. Li, Molecular imprinting: perspectives and applications, Chem. Soc. Rev. 45 (2016) 2137-2211.

[26] Z. Iskierko, P.S. Sharma, K. Bartold, A. Pietrzyk-Le, K. Noworyta, W. Kutner Molecularly imprinted polymers for separating and sensing of macromolecular compounds and microorganisms, Biotechnol. Adv. 34 (2016) 30-46.

[27] N. Tawil, E. Sacher, R. Mandeville, M. Meunier, Strategies for the immobilization of bacteriophages on gold surfaces monitored by surface Plasmon resonance and surface morphology, J. Phys. Chem. C 117 (2013) 6686-6691.

[28] D. Yongabi, M. Khorshid, P. Losada-Pérez, K. Eersels, O. Deschaume, J. D'Haen, C. Bartic, J. Hooyberghs, R. Thoelen, M. Wübbenhorst, P. Wagner, Cell detection by surface imprinted polymers SIPs: a study to unravel the recognition mechanisms, Sens. Actuators B 255 (2018) 907-917.

[29] J.E. Lofgreen, G.A. Ozin, Controlling morphology and porosity to improve performance of molecularly imprinted sol-gel silica, Chem. Soc. Rev. 43 (2014) 911-933.

[30] S.J. Li, S.S. Cao, M.J. Whitcombe, S.A. Piletsky, Size matters: challenges in imprinting macromolecules, Prog. Polym. Sci. 39 (2013) 145-163.

[31] M.F. Jia, Z. Zhang, X.B. Yang, J.H. Li, L.X. Chen, Design and application of novel molecular imprinting fluorescent sensors, Sci. Sin. Chim. 47 (2017) 300-314.

[32] M. Darder, P. Aranda, L.B. Asperilla, A. Llobera, V.J. Cadarso, F.C. Sanchez, E.R. Hitzky, Algae-silica systems as functional hybrid materials, J. Mater. Chem. 20 (2010) 9362-9369.

[33] G.M. Birnbaumer, P.A. Lieberzeit, L. Richter, R. Schirhagl, M. Milnera, F.L. Dickert, A. Bailey, P. Ertl, Detection of viruses with molecularly imprinted polymers integrated on a microfluidic biochip using contact-less dielectric microsensors, Lab Chip 9 (2009) 3549-3556.

[34] A. Seifner, P. Lieberzeit, C. Jungbauer, F.L. Dickert, Synthetic receptors for selectively detecting erythrocyte ABO subgroups, Anal. Chim. Acta 6510 (2009) 215-219.

[35] T. Cohen, J. Starosvetsky, U. Cheruti, R. Armon, Whole cell imprinting in sol-gel thin films for bacterial recognition in liquids: macromolecular fingerprinting, Int. J. Mol. Sci. 11 (2010) 1236-1252.

[36] B. Zdyrko, Toward protein imprinting with polymer brushes, Biointerphases 4 (2009) FA17-FA21.

[37] J. Starosvetsky, T. Cohen, U. Cheruti, D. Bilanović, R. Armon, Effects of physical parameters on bacterial cell adsorption onto pre-imprinted sol-gel films, J. Biomater. Nanobiotechnol. 3 (2012) 499-507.

[38] R. Schirhagl, E.W. Hall, I. Fuereder, R.N. Zare, Separation of bacteria with imprinted polymeric films, Analyst 137 (2012) 1495-1499.

[39] Y.T. Wang, Z.Q. Zhang, V. Jain, J.J. Yi, S. Mueller, J. Sokolov, Z.X. Liu, K. Levon, B. Rigas, M.H. Rafailovich, Potentiometric sensors based on surface molecular imprinting: detection of cancer biomarkers and viruses, Sens. Actuators B 146 (2010) 381-387.

[40] M.A.R. Khan, F.T.C. Moreira, J. Riu, M.G.F. Sales, Plastic antibody for the electrochemical detection of bacterial surface proteins, Sens. Actuators B 233 (2016) 697-704.

[41] R.I. Boysen, L.J. Schwarz, D.V. Nicolau, M.T.W. Hearn, Molecularly imprinted polymer membranes and thin films for the separation and sensing of biomacromolecules, J. Sep. Sci. 40 (2017) 314-335.

[42] R. Schirhagl, K.N. Ren, R.N. Zare, Surface imprinted polymers in microfluidic devices, Sci. Sin. Chim. 42 (2012) 937-953.

[43] S. Sykora, A. Cumbo, G. Belliot, P. Pothier, C. Arnal, Y. Dudal, P. Corvini, P. Shahgaldian, Virus-like particles as virus substitutes to design artificial virus-recognition nanomaterials, Chem. Commun. 51 (2015) 2256-2258.

[44] Z. Altintas, J. Pocock, K.A. Thompson, I.E. Tothill, Comparative investigations for adenovirus recognition and quantification: plastic or natural antibodies? Biosens. Bioelectron. 74 (2015) 996-1004.

[45] R. Hu, J.Y. Luan, E.D. Kharasch, S. Singamaneni, J.J. Morrissey, Aromatic functionality of target proteins influences monomer selection for creating artificial antibodies on plasmonic biosensors, ACS Appl. Mater. Interfaces 9 (2017) 145-151.

[46] M. Cieplak, W. Kutner, Artificial biosensors: how can molecular imprinting mimic biorecognition? Trends Biotechnol. 34 (2016) 922-941.

[47] R. Schirhagl, P.A. Lieberzeit, F.L. Dickert, Chemosensors for viruses based on artificial immunoglobulin copies, Adv. Mater. 22 (2010) 2078-2081.

[48] Z.J. Zhang, M. Li, J.S. Ren, X.G. Qu, Cell-imprinted antimicrobial bionanomaterials with tolerable toxic side effects, Small 11 (2015) 1258-1264.

[49] Z.J. Zhang, J.W. Liu, Molecularly imprinted polymers with DNA aptamer fragments as macromonomers, ACS Appl. Mater. Interfaces 8 (2016) $6371-6378$.

[50] M.R. Chao, C.W. Hu, J.J. Chen, Fluorescent turn-on detection of cysteine using a molecularly imprinted polyacrylate linked to allylthiol-capped CdTe quantum dots, Microchim. Acta 181 (2014) 1085-1091.
[51] W. Zhang, W. Liu, P. Li, H.B. Xiao, H. Wang, B. Tang, A fluorescence nanosensor for glycoproteins with activity based on the molecularly imprinted spatial structure of the target and boronate affinity, Angew. Chem. Int. Ed. 53 (2014) $12489-12493$.

[52] E.B. Pena, M.G. Valdesb, B.G. Martínez, Fluorescence based fiber optic and planar waveguide biosensors. A review, Anal. Chim. Acta 943 (2016) 17-40.

[53] M. Gao, F.B. Yu, C.J. Lv, J. Choo, L.X. Chen, Fluorescent chemical probes for accurate tumor diagnosis and targeting therapy, Chem. Soc. Rev. 46 (2017) 2237-2271.

[54] H.S. Qian, H.C. Guo, P.C.L. Ho, R. Mahendran, Y. Zhang, Mesoporous-silicacoated up-conversion fluorescent nanoparticles for photodynamic therapy, Small 5 (2009) 2285-2290.

[55] L.Y. Zhu, W.W. Wu, M.Q. Zhu, J.J. Han, J.K. Hurst, D.Q.L. Alexander, Reversibly photoswitchable dual-color fluorescent nanoparticles as new tools for livecell imaging, J. Am. Chem. Soc. 129 (2007) 3524-3526.

[56] D.K. Chatterjee, M.K. Gnanasammandhan, Y. Zhang, Small upconverting fluorescent nanoparticles for biomedical applications, Small 6 (2010) 2781-2795.

[57] R.H. Liu, Q.L. Cui, C. Wang, X.Y. Wang, Y. Yang, L.D. Li, Preparation of sialic acid-imprinted fluorescent conjugated nanoparticles and their application for targeted cancer cell imaging, ACS Appl. Mater. Interfaces 9 (2017) 3006-3015.

[58] C.S. Liang, H. Wang, K. He, C.Y. Chen, X.M. Chen, H. Gong, C.Q. Ca, A virus-MIPs fluorescent sensor based on FRET for highly sensitive detection of JEV, Talanta 160 (2016) 360-366.

[59] S.F. Chen, X.Q. Chen, L.J. Zhang, J.J. Gao, Q. Ma, Electrochemiluminescence detection of Escherichia coli 0157:H7 based on a novel polydopamine surface imprinted polymer biosensor, ACS Appl. Mater. Interfaces 9 (2017) 5430-5436.

[60] F. Shahzad, S.A. Zaidi, C.M. Koo, Highly sensitive electrochemical sensor based on environmentally friendly biomass-derived sulfur-doped graphene for cancer biomarker detection. Sens. Actuators B 241 (2017) 716-724.

[61] W. Suginta, P. Khunkaewla, A. Schulte, Electrochemical biosensor applications of polysaccharides chitin and chitosan, Chem. Rev. 113 (2013) 5458-5479.

[62] D. Grieshaber, R. MacKenzie, J. Vörös, E. Reimhult, Electrochemical biosensorssensor principles and architectures, Sensors 8 (2008) 1400-1458.

[63] A. Namvar, K. Warriner, Microbial imprinted polypyrrole/poly (3- methylthiophene) composite films for the detection of Bacillus endospores, Biosens Bioelectron. 22 (2007) 2018-2024.

[64] Z.J. Zhang, Y.J. Guan, M. Li, A.D. Zhao, J.S. Ren, X.G. Qu, Highly stable and reusable imprinted artificial antibody used for in situ detection and disinfection of pathogens, Chem. Sci. 6 (2015) 2822-2826.

[65] Z.O. Uygun, H.D.E. Uygun, N. Ermis, E. Canba, Molecularly imprinted sensorsNew sensing technologies, in: Biosensors-micro and nanoscale applications, 2015, pp. 86-108.

[66] G. Marrazza, Piezoelectric biosensors for organophosphate and carbamate pesticides: a review, Biosensors 4 (2014) 301-317.

[67] M.E. Escuderos, S. Sánchez, A. Jiménez, Quartz crystal microbalance (QCM) sensor arrays selection for olive oil sensory evaluation, Food Chem. 124 (2011) 857-862.

[68] A. Kumar, J. Brunet, C. Varenne, A. Ndiaye, A. Pauly, M. Penza, M. Alvisi, Tetratert-butyl copper phthalocyanine-based QCM sensor for toluene detection in air at room temperature, Sens. Actuators B 210 (2015) 398-407.

[69] A. Tretjakov, V. Syritski, J. Reut, R. Boroznjak, O. Volobujeva, A. Öpik, Surface molecularly imprinted polydopamine films for recognition of immunoglobulin G, Microchim. Acta 180 (2013) 1433-1442.

[70] R. Samardzic, H.F. Sussitz, N. Jongkon, P.A. Lieberzeit, Quartz crystal microbalance in-line sensing of escherichia coli in a bioreactor using molecularly imprinted polymers, Sens. Lett. 12 (2014) 1152-1155.

[71] A. Schnettelker, P. Lieberzeit, A self-organisation synthesis approach for bacteria molecularly imprinted polymers, Procedia Eng. 168 (2016) 557-560.

[72] P. He, L.J. Liu, W.P. Qiao, S.S. Zhang, Ultrasensitive detection of thrombin using surface Plasmon resonance and quartz crystal microbalance sensors by aptamer-based rolling circle amplification and nanoparticle signal enhancement, Chem. Commun. 50 (2014) 1481-1484.

[73] U. Latif, S. Can, O. Hayden, P. Grillberger, F.L. Dickert, Sauerbrey and antiSauerbrey behavioral studies in QCM sensors-Detection of bioanalytes, Sens. Actuators B 176 (2013) 825-830.

[74] U. Latif, J.J. Qian, S. Can, F.L. Dickert, Biomimetic receptors for bioanalyte detection by quartz crystal microbalances - from molecules to cells, Sensors 14 (2014) 23419-23438.

[75] A.M. Shrivastav, S.P. Usha, B.D. Gupta, Highly sensitive and selective erythromycin nanosensor employing fiber optic SPR/ERY imprinted nanostructure: application in milk and honey, Biosens. Bioelectron. 90 (2017) 90516-90524.

[76] H. Agrawal, A.M. Shrivastav, B.D. Gupta, Surface plasmon resonance based optical fiber sensor for atrazine detection using molecular imprinting technique, Sens. Actuators B 227 (2016) 204-211.

[77] S.P. Usha, S.K. Mishra, B.D. Gupta, Fabrication and characterization of a SPR based fiber optic sensor for the detection of chlorine gas using silver and zinc oxide, Materials 8 (2015) 2204-2216.

[78] Z. Altintas, M. Gittens, A. Guerreiro, K.A. Thompson, J. Walker, S. Piletsky, I.E. Tothill, Detection of waterborne viruses using high affinity molecularly imprinted polymers, Anal. Chem. 87 (2015) 6801-6807.

[79] E. Yilmaz, D. Majidi, E. Ozgur, A. Denizli, Whole cell imprinting based Escherichia coli sensors: a study for SPR and QCM, Sens. Actuators B 209 (2015) 714-721. 
[80] S.S. Wang, D.Y. Yin, W.J. Wang, X.J. Shen, J.J. Zhu, H.Y. Chen, Z. Liu, Targeting and imaging of cancer cells via monosaccharide-imprinted fluorescent nanoparticles, Sci. Rep. 6 (2016) 22757-22768.

[81] T.S.C.R. Rebelo, J.P. Noronha, M. Galésio, H. Santos, M. Diniz, M.G.F. Sales M.H. Fernandes, J.C. Rodrigues, Testing the variability of PSA expression by different human prostate cancer cell lines by means of a new potentiometric device employing molecularly antibody assembled on graphene surface, Mater. Sci. Eng. C 59 (2016) 1069-1078.

[82] B.W. Brooks, J. Devenish, C.L. Lutze-Wallace, D. Milnes, R.H. Robertson, G.B. Surujballi, Evaluation of a monoclonal antibody-based enzyme-linked immunosorbent assay for detection of Campylobacter fetus in bovine preputial washing and vaginal mucus samples, Vet. Microbiol. 103 (2004) 77-84.

[83] E. Roy, S. Patra, A. Tiwari, R. Madhuri, P.K. Sharma, Single cell imprinting on the surface of $\mathrm{Ag}-\mathrm{ZnO}$ bimetallic nanoparticle modified graphene oxide sheets for targeted detection, removal and photothermal killing of E. Coli, Biosens. Bioelectron. 89 (2017) 620-626.

[84] L. Torrance, A. Ziegler, H. Pittman, M. Paterson, R. Toth, I. Eggleston, Oriented immobilisation of engineered single-chain antibodies to develop biosensors for virus detection, J. Virol. Methods 134 (2006) 164-170.

[85] F. Zezza, M. Pascale, G. Mulè, A. Visconti, Detection of Fusarium culmorum in wheat by a surface Plasmon resonance-based DNA sensor, J. Microbiol. Methods 66 (2006) 529-537.
[86] P. Skottrup, S. Hearty, H. Frøkiær, P. Leonard, J. Hejgaard, R. Kennedy, M. Nicolaisen, A.F. Justesen, Detection of fungal spores using a generic surface plasmon resonance immunoassay, Biosens. Bioelectron. 22 (2007) 2724-2729.

[87] A.M. Poller, E. Spieker, P.A. Lieberzeit, C. Preininger, Surface imprints: advantageous application of ready2use materials for bacterial quartz-crystal microbalance sensors, ACS Appl. Mater. Interfaces 9 (2017) 1129-1135.

[88] F.L. Dickert, O. Hayden, R. Bindeus, K.J. Mann, D. Blaas, E. Waigmann, Bioimprinted QCM sensors for virus detection -screening of plant sap, Anal. Bioanal. Chem. 378 (2004) 1929-1934.

[89] J. Borovicka, W.J. Metheringham, L.A. Madden, C.D. Walton, S.D. Stoyanov, V.N. Paunov, Photothermal colloid antibodies for shape-selective recognition and killing of microorganisms, J. Am. Chem. Soc. 135 (2013) 5282-5285.

[90] S. Tokonami, Y. Nakadoi, M. Takahashi, M. Ikemizu, T. Kadoma, K. Saimatsu, L.Q. Dung, H. Shiigi, T. Nagaoka, Label-free and selective bacteria detection using a film with transferred bacterial configuration, Anal. Chem. 85 (2013) 4925-4929.

[91] S. Tokonami, Y. Nakadoi, H. Nakata, S. Takami, T. Kadoma, H. Shiigi, T. Nagaoka, Recognition of gram-negative and gram-positive bacteria with a functionalized conducting polymer film, Res. Chem. Intermed. 40 (2014) 2327-2335.

[92] K. Seidler, M. Polreichová, P.A. Lieberzeit, F.L. Dickert, Biomimetic yeast cell typing-application of QCMs, Sensors 9 (2009) 8146-8157.

[93] S. Tang, H. Zhang, H.K. Lee, Advances in sample extraction, Anal. Chem. 88 (2016) 228-249. 